\title{
Evaluating the Effects of Global Environmental Changes on Ecosystems via Mycorrhizae, Soil Biota and Plant Traits
}

\author{
Mukete Beckline, Sun Yujun ${ }^{*}$ \\ Laboratory for Silviculture and Conservation, Beijing Forestry University, 35 Qinghua East Road, Box 117 Beijing, China \\ *Corresponding author: sunyj@bjfu.edu.cn
}

Received November 01, 2014; Revised December 06, 2014; Accepted December 18, 2014

\begin{abstract}
Global environmental change (GEC) which is a change in average weather conditions due to biotic and abiotic processes and human activities, affects above and belowground organisms such as mycorrhizae, soil biota and plants. As with other major components of terrestrial ecosystems, the trait responses of these above and below ground organisms to GEC have received limited attention. Most of the research have been pot-based with a few field especially monoculture studies using mycorrhizal traits. A major question that arises from all these studies is, whether the GEC effects on mycorrhizal fungi, soil biota and plant traits can directly influence ecosystem functions. This paper looks at the effects of GEC on ecosystems via mycorrhizal fungi traits such as speed of root colonization, hyphal length; soil biota traits such as running speed, palatability and plant traits such as seed size, shoot phenology and how these may retroact to influence ecosystem functions such as nutrient and carbon cycling.
\end{abstract}

Keywords: precipitation, temperature, mycorrhizae, Collembola, traits, nutrient cycling and global environmental change

Cite This Article: Mukete Beckline, and Sun Yujun, "Evaluating the Effects of Global Environmental Changes on Ecosystems via Mycorrhizae, Soil Biota and Plant Traits.” Applied Ecology and Environmental Sciences, vol. 2, no. 6 (2014): 135-140. doi: 10.12691/aees-2-6-2.

\section{Introduction}

Global Environmental Change (GEC) is a change in average weather conditions due to biotic/abiotic processes and human activities [1,2]. Over the past century, human activities have released large amounts of greenhouse gases (GHGs) including carbon dioxide into the atmosphere. Arising mostly from fossil fuels combustion and agricultural practices, these GHGs have resulted to dangerous effects on man and his environment [2,3,4,5].

These major disturbances due to GEC, drive ecosystem performance and indirectly affect soil biota. Soil biota are important regulators of global biogeochemical cycling, responsible for mineralizing organic nutrients and atmospheric carbon exchange [6]. Evidence suggests that depending on the community composition, soil biotamediated ecosystem functioning substantially varies within environments [7,8,9].

By considering trade-offs in ecophysiological, morphological and life-history traits, mechanistic linkages between fundamental biology, community dynamics and ecosystem functioning have been provided [10-14]. Therefore due to their predictable distributions at global and regional scales, it is necessary to incorporate soil biota processes into Earth system models (ESM) such as to improve our understanding of biogeochemical cycles and their feedbacks to global climate change $[15,16,17]$.
These ecosystem performances and changes occur aboveground through a change in plant community composition, carbon allocation patterns or the quantity and quality of plant-derived organic matter $[18,19,20]$. These predicted changes due to GEC, may directly affect vegetation via plant traits (leaf size, palatability) and indirectly via soil biota traits (running speed, vertical stratification) [21,22] and via symbiotic mycorrhizal traits (mycelium structure, hyphal length). This is because mycorrhizae improve host plant nutrition, especially under unfavorable environmental conditions [23] and increase plant stress tolerance [24]. They are important in main ecosystem processes such as carbon cycling and nutrient mobilization because they link plant and soil [25]. In forests, trees are usually colonized by a large number of different mycorrhizal species [26,27,28].

Though these GEC impacts for ecosystem performance are widely recognized, the mechanisms that drive the responses to them are not well known. Therefore, understanding these consequences requires explicit consideration of linkages between aboveground and belowground biota.

In this study, we carry-out a literature survey to assess how predicted GEC may directly or indirectly affect ecosystem functions via impacts on mycorrhizal, soil biota e.g. Springtails and plant traits. Our general assumption is that, should the predicted GEC affect mycorrhizal fungi traits, this will in turn influence plant photosynthate acquisition of carbon, nutrient cycling and decomposition 
rate, hence affecting ecosystem performance (Figure 1). The paper has been divided into three sections with the first looking at global environmental changes and mycorrhizal traits. In this section, we discuss the probable effects of GEC on mycorrhizal traits (hyphal length, root colonization) and how this may retroact on ecosystem processes. In the second section, we explore the probable links between GEC, soil biota traits such as Springtails
(Collembolla) traits (running speed, vertical stratification) and ecosystem processes. In the third section, we highlight the implications of these changes on ecosystem functions through plant traits (leaf size, shoot phenology). We then conclude that, trait-based approaches can provide a tractable set of tools for understanding the links between GEC and ecosystem functioning.

\section{Global change, mycorrhizae and ecosystem functions}

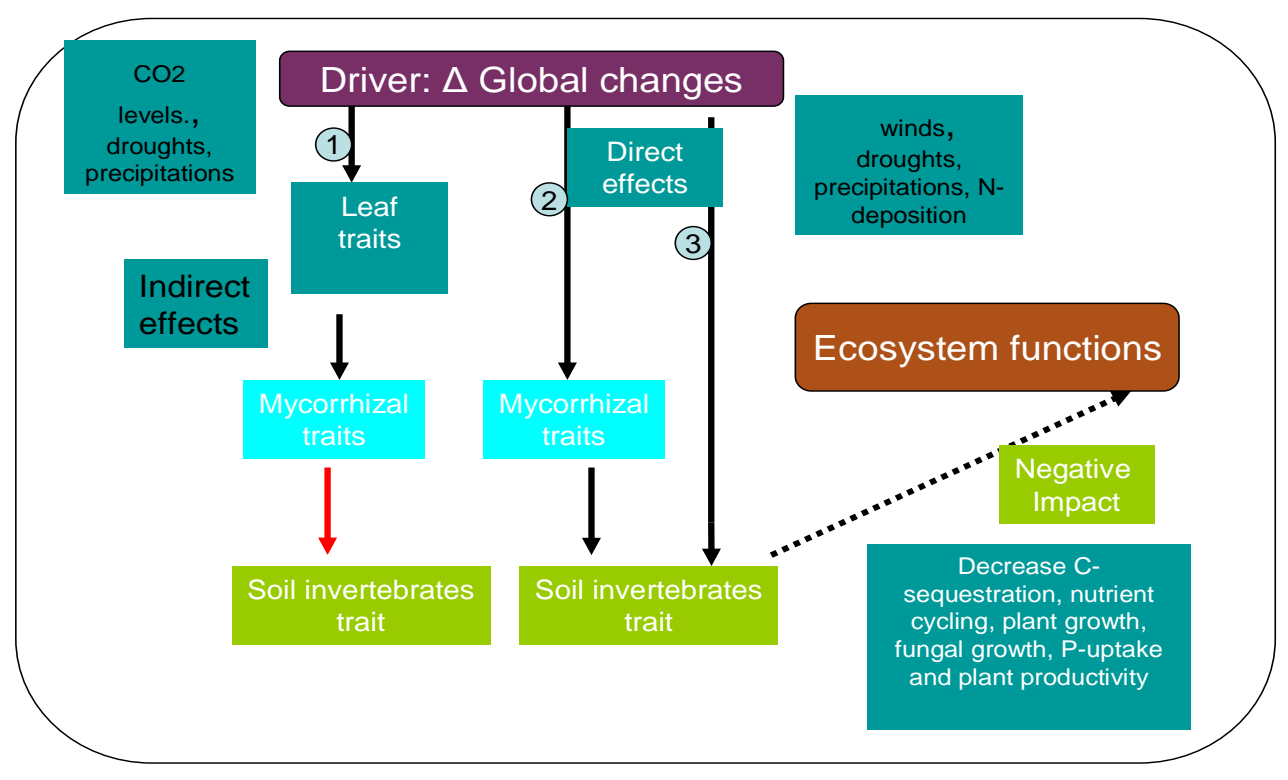

Figure 1. Relationship between global environmental changes, plant traits and ecosystem functions

1-Direct effects of global changes via leaf traits

2-Direct effects of global changes via Mycorrhizal traits

3-Direct effects of global changes via Soil invertebrate traits while the dotted lines represent the indirect effects of global changes on ecosystem functions

\section{Global Environmental Changes and Mycorrhizal Traits}

Traits are measurable properties of organisms that are used comparatively across individuals and that can influence an organism's performance or fitness [6]. These can be morphological (structural) and physiological (functional) traits with both categories referring to response traits (that govern how organisms respond to different conditions) and effect traits (that determine how organisms affect their environment). These can relate to biotic (e.g., competitive ability) or abiotic factors (e.g., drought tolerance) and are a product of the expression of multiple true traits (e.g., growth rate or osmolyte production [6].

Using experiments with plants and soil organisms $[20,29]$ showed that, mycorrhizal species can help the host plant to take up nutrient elements and water from soil, in exchange of photosynthetically fixed carbon. Therefore, mycorrhizal species possess organismal traits that influence ecosystem functioning and GEC would modify these relationships and alter certain functions such as soil carbon availability [20,30]. This will be due to a modification in mycorrhizal traits such as spore production, speed of root colonization, amount of root colonization and frequency of hyphal fusions. Changes in these traits will therefore affect the physiological activities of plant nutrient uptake and transport pathways [19,31,32,33]. Similarly, in cases where mycorrhizal fungi transfer significant amounts of $\mathrm{N}$ to the plant due to temperature increase, soil texture loss and drought, mycorrhizal $\mathrm{N}$ acquisition would be an important functional trait [34].

Also in cases of GEC induced droughts, soil water availability will drop with a complimentary loss in soil moisture and texture with negative effects on root colonization rates, hyphal length and life span [35]. Added to these, are formation and stability of soil aggregates which may change due to land use and fertilizer applications with impacts on ecosystem functions [36,37]. Studying mycorrhizal-plant interactions [38,39,40] affirmed that, continental interiors may experience more frequent and intense droughts due to GEC with a consequence for mycorrhizal root colonization depending on where the host plant is on the stress continuum at the onset of drought. Furthermore, host plant-mycorrhizal relationships at the ends of the host-plant stress gradient may be most sensitive to GEC as mycorrhizal spores and abundance may be lowest in these areas. This is because, GEC affecting relative humidity, temperature, soil 
moisture as well as as precipitation will greatly affect mycorrhizal traits [38-42].

There exist some slight disparities in the GEC studies on mycorrhizal traits, plant interactions and ecosystem functions. For instance, while [43] suggested that structural and physiological changes associated with environmental factors may occur among species [44] concluded that, environmental variability did not influence the discrimination between mycorrhizal species. Studying micro-climatic heterogeneity and differences in soil structure and biochemistry caused by human induced tree species diversity [22,45] concluded that, mycorrhizal species differ in their preference for substrates and exhibit niche partitioning. [22,45] suggested that, this may result in specific patterns of resource utilization such as higher microbial biomass and mineralization rate causing larger leaf litter nitrogen input to the soil.

\subsection{Mycorrhizal Morphological Traits}

The size or extent of many mycorrhizal traits are clearly important under GEC but identifying which are most influential is difficult. As described by $[6,30,38,39,40,42,46,47,48]$ we hereby present and elucidate some major traits as could be affected by GEC.

Reduced soil moisture, relative humidity and precipitation due to GEC, will reduce hyphal length leading to less soil stability, aggregation and plant nutrient acquisition hence plant productivity. Similarly, mycelium structure will be destroyed or distorted due to temperature and precipitation variations especially for the Ectomycorrhizae due to GEC induced strong winds. Furthermore, GEC induced high precipitations (severe rains or snows) will distort mycelial structure consequently affecting plant nutrient acquisition and productivity. The stability of hyphal networks (e.g. occurrence of hyphal fusions) is distorted by GEC induced soil disturbance or disaggregation. This soil disturbance resulting from GEC induced land use changes destroy hyphal networks. This reduces plant resilience with a decrease in plant nutrient acquisition hence affecting ecosystem functions. Similarly, hyphal life span is a very intricate trait in mycorrhizae, should GEC induce soil texture collapse and low soil moisture as a result of temperature variations [41]. This will affect carbon storage with a reduction in nutrient acquisition hence reduced nutrient cycling [6,30,38,39,40,42,46,47,48,49]. GEC induced low soil water and moisture will affect speed of root colonization especially in clay soils. This will impact mycorrhizal spore and seedling establishment thereby affecting plant productivity. Moreso, degree of root colonization is mainly favoured by excess water, oxygen and favourable temperatures. If temperatures increase or if precipitations and soil moisture drop due to GEC, there will be a consequent drop in degree of root colonization. This will hinder protection against fungal pathogens, nutrient acquisition and plant productivity will be affected [41]. Though GEC induced heavy winds may assist in mycorrhizal spore dispersal, it affects spore production, seedling establishment and development since it is usually accompanied by variations in weather conditions (extreme events) [6,30,38,39,40,42,46,47,48,49].

\subsection{Mycorrhizal Physiological Traits}

Physiological diversity and complementary resource use efficiency of nutrient uptake, is greatly influenced by ambient temperatures, precipitations, soil texture; moisture and soil invertebrates. An adverse effect due to GEC will reverse the positive trend in plant nutrient acquisition, plant productivity; phosphorus, nitrogen, copper and iron uptake [38,39]. Also, temporal and spatial variation in fungal activity will be affected by GEC. This is a very direct impact via changes in precipitation regimes, increase in adverse temperatures and human induced land use changes. It directly affects processes like nutrient acquisition and uptake; because this decreases complementary resource use consequently reducing or stopping plant productivity, fungal carbon acquisition and carbon storage. Furthermore, host preference and functional compatibility are influenced by GEC because of habitat fragmentation or invasive and migratory species entering new ecosystems. These species will impact on their new ecosystem hence GEC such as increase in temperatures influence habitat composition. For instance, semi-arid regions with a particular plant species may become arid regions and thus, adaptive species will be extinct, therefore new plant (non-adaptive) hosts will be introduced. This will greatly affect the plant community structure hence, diversity and productivity $[6,30,38,39,40,42,46,47,48]$. Also, GEC predictions on mycorrhizal abundance and community structure can be done through adjacent sites with similar soil parameters but different levels of host-plant stress. $\mathrm{P}$ uptake by plants for instance, is related to the amount of external hyphae produced by a specific mycorrhizae. Plants colonized by mycorrhizal types that produce large amounts of external mycelium usually acquire more $\mathrm{P}$ from mycorrhizae compared with plants that are colonized by mycorrhizae that form low amounts of hyphae $[27,49]$. Similarly, plant communities grown with mycorrhizae that produce an extensive mycelium acquire more $\mathrm{P}$ compared with plant communities that are colonized by mycorrhizal producing few hyphae [38,39]. Hence, the hyphal length of mycorrhizal fungi present in the soil could be used to make predictions about the mycorrhizal contribution to plant $\mathrm{P}$ acquisition and plant productivity (especially in cases where $\mathrm{P}$ is limiting plant growth).

\section{Soil Biota e.g. Springtails (Collembola) Traits}

The symbiosis between host plant and mycorrhizae is influenced by several biotic and abiotic parameters [50]. One of the important mezofaunal groups $(0.1-2 \mathrm{~mm})$ is the springtails (Collembola) which are abundant microarthropods in virtually all soils, feeding on a range of materials, including fungi, bacteria, lichens, decomposing vegetation and detritus. These Collembola feed on fungi and bacteria in the soil thus play an important regulatory role in the interrelationship of mycorrhizae and host plants. Collembola can influence colonization, mycelium size and structure, abundance and nutrient uptake of plants through the mycorhizae. It has been suggested that these animals reduce the functioning of the mycorhizae by feeding on their hyphae and spores [31,50,51]. Several studies [50,52,53,54] have affirmed a relationship between Collembolan density, grazing and 
mycorrhizal colonization or plant soil nutrient acquisition, herbivory and C-N ratio in plant leaves.

[54] suggested that, plant species distribution are influenced by environmental factors including mycorrhizae (total hyphal length and diversity of darklypigmented microfungi). This study posited that, GEC may affect soil invertebrate traits such as running speed, body size and that when temperature rises, vertical stratification becomes negative. The invertebrates move further down the soil, thus affecting and reducing grazing because there are no mycorrhizae deep. Animals migrate vertically in the soil, driven or attracted by changes in temperature, moisture and fungal biomass. Furthermore, $[17,38,39,55,56]$ concluded that, microarthropods have minimal direct effect on roots and mycorrhizal spores but may strongly influence the extra-radical hyphal network of mycorrhizae. This is because grazing of the extraradical hyphae of mycorrhizal fungi by arthropods has the potential to reduce the efficacy of mycorrhizal associations, mainly by limiting the transport of mineral nutrients to roots.

Soil arthropods are abundant in many soils influencing fungal communities indirectly via communication, channeling and mixing and directly through grazing and dispersal of spores [19,38,39,50,57]. Hence on a large scale, microarthropod community composition changes in response to changes in the plant community occurring along environmental gradients. On a smaller scale, the community is affected by spatial heterogeneity in microclimate. According to [19], temporal changes also occur in the long-term, as a result of successional processes or predictable seasonal shifts such as from GEC.

Invasion or extinction of free living and mutualistic soil biota with unique traits may alter ecosystem processes by modifying the availability of soil resources to plants [51,57]. Furthermore, changes in vegetation composition involving species with unique traits may have large-scale impacts as they affect the utilization of resources by freeliving and mutualistic soil biota. This mostly occurs through alterations in the amount, quality and distribution of litter or exudates produced. Finally, changes in engineering activities or in antagonistic effects may alter ecosystem processes by modifying the disturbance regime experienced by those organisms on one side of the above and belowground interface [51,58].

Similarly, the ability to degrade recalcitrant organic substrates, such as lignin or humic substances, is confined to a few microbial genera. A greater buildup of litter on the soil surface due to the loss of organisms able to break down recalcitrant materials may drastically alter the availability of nutrients to plants [59]. Mutualistic soil organisms may display traits related to the supply of soil resources to plants that are unique to a few species or conditions. Changes in species composition are thus expected to alter the availability of soil resources to plants in the former but not the latter case. This change is likely when GEC induced change overrides all other factors controlling plant assemblage structure with erosion of key plant attributes such as C gain [19].

Collembola are capable of grazing on arbuscular mycorrhiza (AM) hyphae and spores but these are not probably their preferred food when other food sources are available [51]. AM fungi are less palatable to Collembolans compared with other fungi and this palatability mechanism is still unclear but several studies $[58,60,61,62,63]$ suggest that, it may be due to hyphal architecture, reproductive and nutritive value, biochemical or metabolic features and hyphal dark pigmentation.

\section{Plant Traits}

A consistent link between GEC and major ecosystem processes using plant traits, is hard to trace. However $[59,64,65]$ suggested the existence of such links across different environmental gradients. Similarly, [66,67] affirmed that, the predicted GEC would affect certain plant traits such as seed size, leaf thickness, seed shape and mass, hence, ecosystem functions. Furthermore, GEC induced water, nutrient and temperature stresses would lead to convergent trait syndrome such as a reduction in specific leaf area, leaf thickness, seed size, shape and mass and shoot phenology [66,67]. Therefore, the protection of photosynthetic tissues from external agents especially desiccation and herbivory would be lost due to loss in leaf tensile strength and leaf thickness. The protection of photosynthetic tissues is achieved through slightly different traits e.g. inrolling lamina in graminoids, thickened cuticle in succulents or shoot phenology and seed mass. Therefore, any changes in abiotic and biotic habitat conditions due to GEC, would affect these traits. This will consequently entail poor nutrient acquisition, carbon sequestration and reduced primary production by plants thus affecting ecosystems functioning $[57,68,69]$.

\section{Conclusions}

Symbiotic mycorrhizal fungi are functionally diverse with their composition having a large impact on plant performance, plant community structure and ecosystem functioning. Few studies have made a direct link between the composition of mycorrhizal communities in the field and their functional significance for plant growth and ecosystem functioning. Generally, field and laboratory mycorrhizal studies have proven that, GEC will obviously affect trait compositions of mycorrhizae via weather changes such as increase in ambient temperatures, drop in precipitations, land use changes, carbon sequestration and via changes in plant host preferences.

Also, soil arthropods may influence fungal communities indirectly via communication, channeling or mixing and directly through grazing or dispersal of spores, wherefore their role in ecosystem functioning with regards to GEC should not be underemphasized. Nevertheless, this is an area that needs much more attention, not only to better understand the ecology of plants and plant communities but also to monitor whether introductions of mycorrhizae into the field have been successful. Therefore, highlighting functional traits that could be used to predict the effects of mycorrhizal communities on plant growth and ecosystem functioning, together with microcosm studies and novel technologies will help to better understand the functional significance of mycorrhizae for plants, ecosystems and global changes.

\section{Acknowledgment}


This study was supported by Project of Forestry Science and Technology Research (No. 2012-07); Special Public Interest Research and Industry Fund of Forestry (No.200904003-1) and Forestry Extension Program of Science and Technology (No.[2014] 26).

\section{References}

[1] Intergovernmental Panel on Climate Change (IPCC 2007) Climate Change 2007: The Fourth Assessment Report. Impacts, Adaptation and Vulnerability. Cambridge University Press

[2] America's Climate Choices (ACC, 2010): Panel on Advancing the Science of Climate Change; National Research Council. Advancing the Science of Climate Change. Washington, D.C: The National Academies Press. ISBN 0-309-14588-0.

[3] Emanuel, K (2005). Increasing destructiveness of tropical cyclones over the past 30 years. Nature 436 (7051):686-688.

[4] Foley, J., DeFries., R., Asner, P., Barford, C., Bonan, G., Carpenter, S., Chpain, F., Coe, T., Daily, G., Gibbs, H., Helkowski, J., Holloway, T., Howard, A., Kucharik, C., Monfreda, C., Patz, J., Pretince, I., Navin, R and Snyder, P (2005). Global consequences of land use. Science 309: 570-574.

[5] United Nations Framework Convention on Climate Change (UNFCCC, 2006). Background papers on impacts, vulnerability and adaptation to climate change in Africa for the African Workshop on adaptation and implementation of decision 1/CPO.10 of the UNFCCC Convention Accra, Ghana 2123.09.2006

[6] Crowther, T., Maynard, D., Crowther, R., Peccia, J., Smith, R and Bradford, M (2014). Untangling the fungal niche: the trait-based approach. Front Microbi 5: 579.

[7] Schimel, P and Schaeffer, S (2012). Microbial control over carbon cycling in soil. Front. Microbiology 3:348.

[8] Strickland, M., Lauber C., Fierer, N and Bradford, A (2014). Testing the functional significance of microbial community composition published by: ecological society of America content in a trusted digital archive. Functional Ecology. 90, 441-451.

[9] van der Wal, A., Ottosson, E., de Boer, W (2014). Neglected role of fungal community composition in explaining variation in wood decay rates. Ecology.

[10] Green, J., Bohannan, M and Whitaker, J (2008). Microbial biogeography: from taxonomy to traits. Science 320: 1039-1043

[11] Allison, S (2012). A trait-based approach for modelling microbial litter decomposition. Ecol. Letters. 15: 1058-1070.

[12] Adler, B., Fajardo, A., Kleinhesselink, A and Kraft, B (2013). Trait-based tests of coexistence mechanisms. Ecologcal Letters 16: 1294-1306.

[13] Powell, R., Anderson I and Rillig, M (2013). A new tool of the trade: plant-trait based approaches in microbial ecology. Plant Soil $365,35-40$.

[14] Herben, T and Goldberg, D (2014). Community assembly by limiting similarity vs. competitive hierarchies: testing the consequences of dispersion of individual traits. Journal of Ecology 102: 156-166.

[15] Todd-Brown, K., Randerson, T., Hopkins, F., Arora, V and Jones C (2013). Changes in soil organic carbon storage predicted by Earth system models during the 21st century. Biogeosciences Discussions 10: 18969-19004.

[16] Wieder, R., Bonan, B and Allison, S (2013). Global soil carbon projections are improved by modelling microbial processes. Nat. Clim. Change. 3, 909-912.

[17] Suz, M., Barsoum, N., Benham, S., Dietrich, H., Fetzer, D., Fischer, R., García, P., Gehrman, J., Kristöfel, F., Manninger, M., Neagu, S., Nicolas, M., Oldenburger, J., Raspe, S., Sánchez, G., Schröck, W., Schubert, A., Verheyen, K., Verstraeten, A and Bidartondo, I (2014). Environmental drivers of ectomycorrhizal communities in Europe's temperate oak forests. Molecular Ecology 23 (22): 5628-5644.

[18] Wardle, D., Verhoef, H and Clarholm, M (1998). Trophic relationships in the soil microfood-web: Predicting the responses to a changing global environment. Global Change Biology 4: 713727.

[19] Read, N., Lichius, A., Shoji, J and Goryachev, B (2009). Selfsignalling and self-fusion in filamentous fungi. Current Opinions Microbiology 12: 608-615.
[20] Cheng, L., Booker, L., Cong, T., Bukey, K., Zhou, L., Shew D., Rufty, W and Shuijin, H (2012). Arbuscular Mycorrhial fungi increase organic carbon decomposition under elevated CO2. Science 337: 1084-1087.

[21] Jonasson S., Chapin, F and Shaver, R (2001). Biogeochemistry in the arctic: patterns, processes and controls. In E.-D. Schulze, M. Heimann, S. Harrison, E. Holland, J.

[22] Lindahl, D., de Boer, W and Finlay, R (2010). Disruption of root carbon transport into forest humus stimulates fungal opportunists at the expense of mycorrhizal fungi. ISME Journal 4: 872-881.

[23] Pena, R and Polle, A (2014). Attributing functions to ectomycorrhizal fungal identities in assemblages for nitrogen acquisition under stress. ISME Journal 8 (2): 321-30.

[24] Schützendübel, A and Polle, A (2002). Plant responses to abiotic stresses: heavy metal-induced oxidative stress and protection by mycorrhization. Journal of Experimental Botany 53 (372): 135165.

[25] Finlay, R (2008). Ecological aspects of mycorrhizal symbiosis: with special emphasis on the functional diversity of interactions involving the extraradical mycelium. Journal of Experimental Botany 59 (5): 1115-26.

[26] Buée, M., Vairelles, D and Garbaye, J (2005).Year-round monitoring of diversity and potential metabolic activity of the ectomycorrhizal community in a beech (Fagus silvatica) forest subjected to two thinning regimes. Mycorrhiza 15 (4): 235-45.

[27] Suz, M., Azul, A., Morris, H., Bledsoe, C and Martín, P (2008). Morphotyping and molecular methods to characterize ectomycorrhizal roots and hyphae in soil, in Molecular Mechanisms of Plant and Microbe Coexistence Soil Biology, eds Nautiyal P. D. C. S., Dion P. D. P., editors. (Berlin, Heidelberg: Springer) 437-474.

[28] Lang, C., Seven, J and Polle, A (2011). Host preferences and differential contributions of deciduous tree species shape mycorrhizal species richness in a mixed Central European forest. Mycorrhiza 21 (4): 297-308.

[29] Nichols, A and Toro, M (2011). A whole soil stability index (WSSI) for evaluating soil aggregation. Soil Tillage Research 111: 99-104.

[30] Johnson, C., Angelard, C., Sanders, I and Kiers, T (2013). Predicting community and ecosystem outcomes of mycorrhizal responses to global change. Ecology Letters, 16, 140-153.

[31] Staddon, P (2005). Mycorrhizal fungi and environmental change: the need for a mycocentric approach. New Phytologist 167 (3) 635-637.

[32] Peng, L., Guo, T and Liu, G (2013). The effects of arbuscular mycorrhizal hyphal networks on soil aggregations of purple soil in southwest China. Soil Biology and Biochemistry 57: 411-417.

[33] Chagnon, L (2014). Ecological and evolutionary implications of hyphal anastomosis in arbuscular mycorrhizal fungi. FEMS Microbiology Ecology 88 (3) 437-444.

[34] Johanssen, J., Paul, L and Finlay, R (1992). Microbial interactions in the mycorrhizosphere and their significance for sustainable agriculture. FEMS Microbiology and Ecology 18: 1-13.

[35] Swaty, R., Deckert, R., Whitham, T and Gehring, C (2004). Ectomycorrhizal abundance and community composition shifts with drought: predictions from tree rings. Ecology 85:1072-1084

[36] Miller, R and Jastrow, J (2000). Mycorrhizal fungi influence soil structure. In: Kapulnik Y, Douds DD, eds. Arbuscular mycorrhizae: molecular biology and physiology. Dordrecht, the Netherlands: Kluwer Academic Press, 3-18.

[37] Wu, Q., Huang, M., Nasrullah, L and He, X (2014). Contribution of arbuscular mycorrhizas to glomalin-related soil protein, soil organic carbon and aggregate stability in citrus rhizosphere. Int. J. Agric. Biology 16: 207-212

[38] Van der Heijden, M., Klironomos, N., Ursic, M., Moutoglis, P., Streitwolf-Engel, R and Boller, T (1998). Mycorrhizal fungal diversity determines plant biodiversity, ecosystem variability and productivity. Nature 396: 72-75.

[39] Van der Heijden, $M$ and Scheublin, $T$ (2007). Functional traits in mycorrhizal ecology: their use for predicting the impact of arbuscular mycorrhizal fungal communities on plant growth and ecosystem functioning. New Phyt 174 (2): 244-250.

[40] van der Heijden, M., Bardgett, D and van Straalen, N (2008). The unseen majority: soil microbes as drivers of plant diversity and productivity in terrestrial ecosystems. Ecology Letters. 11 (3): 296-310. 
[41] Hawkes, V., Kivlin, N., Rocca, D., Huguet, V., Thomsen, M and Suttle, K (2011). Fungal community responses to precipitation Glob Chan Bio 17: 1637-1645.

[42] Chagnon, L., Bradley, R., Maherali, H and Klironomos, J (2013) A trait-based framework to understand life history of mycorrhizal fungi. Trends Plant Sciences 18: 484-491.

[43] Szeghalmi, A., Kaminskyj, S and Gough, K (2007). A synchrotron FTIR microspectroscopy investigation of fungal hyphae grown under optimal and stressed conditions. Anal Bioanal Chemistry 387 (5): 1779-89.

[44] Pena, R., Lang, C., Naumann, A and Polle, A (2014). Ectomycorrhizal identification in environmental samples of tree roots by Fourier-transform infrared (FTIR) spectroscopy. Front Plant Sciences 5: 229.

[45] Guckland, A., Corre, M and Flessa, H (2010). Variability of soil N cycling and $\mathrm{N}_{2} \mathrm{O}$ emission in a mixed deciduous forest with different abundance of beech. Plant Soil 336: 25-38.

[46] Parrent, J., Peay, K., Arnold, E., Comas, H., Avis, P and Tuininga, A (2010). Moving from pattern to process in fungal symbioses: linking functional traits, community ecology and phylogenetics. New Phytologist 185: 882-886.

[47] Johnson, D., Martin, F., Cairney, J and Anderson, I (2012). The importance of individuals: intraspecific diversity of mycorrhizal plants and fungi in ecosystems. New Phytologist 194, 614-628.

[48] Opik, M and Moora, M (2012) Missing nodes and links in mycorrhizal networks. New Phytologist 194: 304-306.

[49] Behm, J and Kiers, T (2014). A phenotypic plasticity framework for assessing intraspecific variation in arbuscular mycorrhizal fungal traits. Journal of Ecology 102: 315-327.

[50] Seres, A., Bakonyi, G and Posta, K (2007). Collembola (Insecta) disperse the arbuscular mycorrhizal fungi in the soil: pot experiment. Polish Journal of Ecology 55: 395-399.

[51] Innocenti, G., Ganassi, S., Matteo, M., Branzanti, B and Sabatini, A (2009). Response of plant growth to Collembola, arbuscular mycorrhizal and plant pathogenic fungi interactions. Bulletin of Insectology 62 (2): 191-195.

[52] Bakonyi, G (1989). Effect of Folsomnia candida (Collembola) on microbial biomass in a grassland soil. Biology and Fertility of Soils 7, 138-141.

[53] McGoningle, (1995). The significance of grazing on fungi in nutrient cycling. Canadian journal of botany 73 (Suppl1) page 1370-1376.

[54] Ganges, A (2000). Arbuscular mycorrhizal fungi, Collembola and plant growth. Trends of Ecology and Evolution 15: 369-372.

[55] Fitter, A and Sanders, I (1992). Interactions with the soil fauna. In Mycorrhizal Functioning. An Integrative Plant-Fungal Process. Ed. M F Allen. pp 333-354. Chapman and Hall, New York.

[56] Lussenhop, J (1996). Collembola as mediators of microbial symbiont effects upon soybean. Soil Biology \& Biochemistry, 28: 363-369.
[57] Cregger, M., Christopher, W., Schadt, N., McDowell, W., Pockman, T and Classen, A (2012). Response of the Soil Microbial Community to Changes in Precipitation in a Semiarid Ecosystem. Applied and Environmental Microbiology 78 (24) 8587-8594.

[58] Klironomos J and Ursic M (1998). Density-dependent grazing on the extra-radical hyphal network of the arbuscular mycorrhizal fungus, Glomus intraradices, by the collembolan, Folsomia candida. Biology and Fertility of Soils 26: 250-253.

[59] Schimel and Gulledge (1998). Moisture effects on microbial activity and community structure in decomposing birch litter in the Alaskan taiga. Soil Biology and Biochemistry 31 (6) 831-838.

[60] Hiol, F., Dixon, R and Curl, A (2004). The feeding preference of mycophagous Collembola varies with the ectomycorrhizal symbiont. Mycorrhiza 5: 99-103.

[61] Sabatini, A and Innocenti, G (2000a). Functional relationships between Collembola and plant pathogenic fungi of agricultural soils. Pedobiologia 44: 467-475.

[62] Maraun, M., Martens, H., Migge, S., Theenhaus, A., Scheu, S (2003). Adding to the 'enigma of soil animal diversity': fungal feeders and saprophagous invertebrates prefer similar food substrates. European Journal of Soil Biology, 39: 85-95.

[63] Larsen, J., Johansen, A., Larsen, E., Eckmann, H., Jakobsen, I and Krogh, P (2008). Population performance of collembolans feeding on soil fungi from different ecological niches. Soil Biology and Biochemistry 40: 360-369.

[64] Hodgson, G., Wilson, J., Hunt, R., Grime, P and Thompson, K (1999). Allocating C-S-R plant functional types: a soft approach to a hard problem. Oikos 85: 282-294.

[65] Lavorel, S and Garnier, E (2002). Predicting changes in community composition and ecosystem functioning from plant traits-revisiting the Holy Grail. Functional Ecology 16: 545-556.

[66] Cunningham, S., Summerhayes, B and Westoby, M (1999). Evolutionary divergences in leaf structure and chemistry, comparing rainfall and soil nutrient gradients. Ecological Monographs 69: 569-588.

[67] Lamont, B., Groom, P and Cowling, M (2002). High leaf mass per area of related species assemblages may reflect low rainfall and carbon isotope discrimination rather than low phosphorus and nitrogen concentrations. Functional Ecology 16: 403-412.

[68] Grubb, P (1998). A reassessment of the strategies of plants which cope with shortages of resources. Perspectives Plant Ecol. Evolut. Syst. 1: 3-31.

[69] Gray, B., Classen, T, Kardol, P., Yermakov, Z and Miller, R (2011). Multiple climate change factors interact to alter soil microbial community structure in an old-field ecosystem. Soil Sci. Soc. Am. J. 75: 2217-2226. 